\title{
Good Clinical Practice
}

\author{
Khalid Aftab* and Sidrah Khan \\ Department of Pharmacology and Therapeutics, Sialkot Medical College, Sialkot and Liaquat National Hospital Medical College, Karachi, Pakistan
}

Submission: April 18, 2019; Published: May 02, 2019

*Corresponding author: Khalid Aftab, Department of Pharmacology and Therapeutics, Sialkot Medical College, Sialkot, Karachi, Pakistan

\section{Editorial}

Drug either form of an active pharmaceutical agent (API) or placebo (a dummy Drug) being used or tested as a standard in a clinical trial [1], including products already with a market availability but used \& manufactured (formulated \& packaged) in a different way from the dosage form, or when used for an indication.

\section{History of Drug Trials}

Drug trials have a long and rich history [2] the first clinical trial documented in the old testament dates back to $605 \mathrm{BC}$, but very brief modern breakthroughs are as follows:

a) In 1929 Alexander Fleming; Penicillin

b) In 1935 Gerhard Domagk; Sulfonamide

c) In 1944 Schatz / Bugie / Waksman; Streptomycin

d) By 1950, the British Medical Research Council developed a systematic methodology for studying \& evaluating therapeutic interventions

e) In 1990, the International Conference on Harmonization (ICH) was announced to help minimize differences in drug development requirements for global Drug markets: The European Union, Japan and United States the International Conference on Harmonization (ICH) policies promote increased efficiency in the development of new Drugs, improving their availability to patients and to the public.

f) In 2000, a Common Technical Document (CTD) has developed. The CTD acts as a standard dossier used in European Union, Japan and the United States for recommending data collected in Drug trials to respective governing authorities etc.

Clinical trials are well structured, critically supervised studies where the safety and efficacy of a new Drug or therapy are tested in an effort to develop new managements that will help those afflicted with the targeted condition. Properly good planned and well executed clinical trials are a powerful experimental tool for examining the effectiveness of an intervention.

\section{Phase I}

Trials evaluate the safety of a Drug. This first phase of testing, which can take many months to complete, usually includes a good number of healthy volunteers (25 to 100), who are generally paid for participating in the trials. The trial is designed to determine the effect of the Drug on healthy humans including how it is behaves or act (absorbed, distributed, bio transformed and eliminated). This phase also examine the adverse effects that occur at different dosage are increased or decreased. About seventy percent of experimental drugs pass this phase of testing.

\section{Phase II}

Trials evaluate the efficacy of a Drug. This second phase of examining can last from many months to two years and involves up to hundreds of patients. Most phase II trials are randomized studies where one group of patients receives the experimental drug, while another "control" group receives a standard treatment or placebo (a dummy Drug). Often these studies are "blind" and "double blind" which mean that neither the patients nor the researchers know who has received the experimental drug. This allows investigators to provide the Pharmaceutical concern and the Food and Drug Administration (FDA) with available information about the relative safety and effectiveness of the new drug. Generally, one-third of experimental drugs successfully complete both Phase I and Phase II trials.

\section{Phase III}

Trials evaluate randomized, cross over and blind testing in several hundred to many thousand patients. This largescale testing, which may require many years, provides the Pharmaceutical concern and the Food and Drug Administration (FDA) with a more thorough understanding of the effectiveness of the drug, the benefits and the range of possible adverse effects. A crossover design is a repeated measurement designed such that each patient receives different treatments during the different time, i.e. the patients cross over from one treatment to another during the course of the clinical trial. Normally, seventy percent to ninety percent of drugs that enter Phase III trials successfully complete this phase of testing. Once Phase III is 
complete, a Pharmaceutical concern can request FDA approval for marketing the drug.

\section{Phase IV}

Trials, often called post Marketing \& Selling surveillance and monitoring studies are conducted after a drug has been approved for patient use. Pharmaceutical concern has several objectives at this stage:

A. To compare a drug with other drugs already in the market;

B. To monitor a drug's long-term effectiveness and impact on a patient's quality of life and

C. To determine the cost-effectiveness (economical) of a drug therapy relative to other traditional and new therapies.

Phase IV clinical trials can result in a drug being taken off the market or restrictions of use could be placed on the product depending on the findings in the studies [3].

\section{Who will involve?}

I. Investigators

II. Coordinator or Project manager
III. Nurses \& paramedics

IV. Pharmacists

V. Laboratory staff etc.

The standard for the designing of Drug trials, conduct, perform, monitor, audit, records, analyses, and reporting that provides assurance of data and reported results are original, accurate and reproducible, that the rights, integrity and confidentiality of trial subjects are protected [4]. Usually it takes ten years for a drug to be developed and approved for prescription from the Food and Drug Administration (FDA).

\section{References}

1. Pocock SJ (2004) Clinical Trials A Practical Approach. John Wiley \& Sons.

2. Collier R (2009) Legumes, Lemons and Streptomycin A short history of the Clinical Trial CMAJ 180: 23-24

3. Van Spall HG, Toren A, Kiss A, Fowler RA (2007) Eligibility criteria of randomized controlled trials published in high-impact general medical journals: a systematic sampling review. JAMA 297(11): 1233-1240.

4. Chow SC, Liu JP (2004) Design and Analysis of Clinical Trials: Concepts and Methodologies.

\begin{tabular}{l} 
Your next submission with Juniper Publishers \\
will reach you the below assets \\
- Quality Editorial service \\
- Swift Peer Review \\
- Reprints availability \\
- E-prints Service \\
- Manuscript Podcast for convenient understanding \\
- Global attainment for your research \\
- Manuscript accessibility in different formats \\
( Pdf, E-pub, Full Text, Audio) \\
- Unceasing customer service \\
Track the below URL for one-step submission \\
https://juniperpublishers.com/online-submission.php \\
\hline
\end{tabular}

